\title{
Crystallochemical characterization of polyoxometalate new minerals
}

Marcelo B Andrade $^{1}$, Daniel Atencio ${ }^{2}$, Javier Ellena ${ }^{1}$

${ }^{1}$ São Carlos Institute Of Physics - University Of São Paulo, SÃo Carlos, Brazil, 2 Institute of Geosciences, University of Sao Paulo, Sao Paulo, Brazil

E-mail: mabadean@terra.com.br

New mineral characterization evolved a lot over time and nowadays requires a combination of good data from advanced analytical methods and techniques such as crystal structure refinement, Raman and IR spectroscopy, electron microprobe and synchrotron X-ray diffraction. Polyoxometalate new minerals are dominated by the Lindqvist hexaniobate ion, $\left(\mathrm{Nb}_{6} \mathrm{O}_{19}\right)^{8^{-}}$, a super-octahedron formed by mutual six edge-sharing of $\mathrm{NbO}_{6}$ octahedra. Polyoxometalate structural features and chemical composition can led to the development of new materials that can be applied to antiviral, antitumoral and antibacterial studies. There are three hexaniobate minerals approved by the Commission on New Minerals, Nomenclature and Classification of the International Mineralogical Association (IMA): melcherite [1], peterandresenite [2] and hansesmarkite [3]. The crystallographic parameters and chemical composition are presented below:

I) melcherite, ideally $\mathrm{Ba}_{2} \mathrm{Na}_{2} \mathrm{Mg}\left[\mathrm{Nb}_{6} \mathrm{O}_{19}\right] \cdot 6 \mathrm{H}_{2} \mathrm{O}$, (IMA 2015-018). The mineral is trigonal, $\mathrm{R}-3$, with $\mathrm{a}=9.0117(6)$, $\mathrm{c}=$ 23.3986(16) $\AA, \beta=118.650(4)^{\circ}, V=1645.64(19) \AA^{3}$ and $Z=3$. Empirical formula based on electron microprobe analyses is: $\left.\left(\mathrm{Ba}_{1.75} \mathrm{~K}_{0.19}\right)_{1.94}\left(\mathrm{Na}_{1.80} \mathrm{Ca}_{19}\right)_{1.99\left(\mathrm{Mg} 0.96 \mathrm{Mno}_{02} \mathrm{Alo} .02\right)}\right)_{1.00 \mathrm{Nb}} .02 \mathrm{O}_{19} \cdot 6 \mathrm{H}_{2} \mathrm{O}$

II) peterandresenite, (IMA 2012-084), ideally $\mathrm{Mn}_{4} \mathrm{Nb}_{6} \mathrm{O}_{19} .14 \mathrm{H}_{2} \mathrm{O}$, monoclinic, $\mathrm{C} 2 / \mathrm{m}$, with $\mathrm{a}=15.329(1), \mathrm{b}=9.4121(5)$, $\mathrm{c}=$ 11.2832(9) $\AA, \beta=118.650(4)^{\circ}, V=1428.6(2) \AA^{3}$ and $Z=2$. Empirical formula based on electron microprobe analyses [2]:

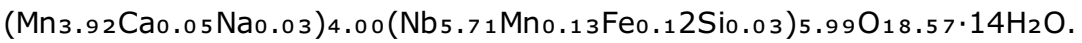

III) hansesmarkite, (IMA 2015-067), ideally $\mathrm{Ca}_{2} \mathrm{Mn}_{2} \mathrm{Nb}_{6} \mathrm{O}_{19} \cdot 20 \mathrm{H}_{2} \mathrm{O}$, triclinic, $\mathrm{P}-1$, with $\mathrm{a}=9.081(4), \mathrm{b}=9.982(8)$, $\mathrm{c}=$ 10.60(1) $\AA, a=111.07(8), \beta=101.15(6), Y=99.39(5)^{\circ}, V=850.8(13) \AA^{3}$ and $Z=1$. Empirical formula based on electron

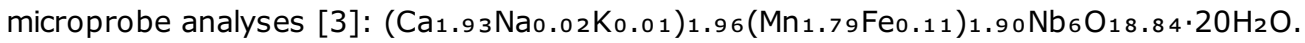

We will discuss the mineral chemical composition, the amount of cation substitution in crystallographic sites, and its influence on polyoxometalate mineral crystallization in three different crystallographic space groups. Understanding of these complex mechanisms is crucial to the prediction of new mineral species and development of new technological applications.

[1] Andrade, M.B. et al. (2015) Min. Mag. 79, 535.

[2] Friis et al. (2014) Eur. J. Min. 26, 567-576.

[3] Friis et al. (2016) Min. Mag. 80, in press.

Keywords: polyoxometalate, melcherite, hansesmarkite 